\title{
Healthier food choices for children through menu pricing
}

\author{
by Kellershohn, J., Walley, K. and Vriesekoop, F.
}

Copyright, Publisher and Additional Information: This is the author accepted manuscript. The final published version (version of record) is available online via Emerald

Please refer to any applicable terms of use of the publisher.

DOI: https://doi.org/10.1108/BFJ-08-2016-0379 


\section{Introduction}

Food choice can impact health and with the rapidly rising number of meals eaten at fast food restaurants by children there is concern regarding the effects of less healthy food choices (Anderson and Mirosa, 2014). There is a general lack of data on 'how and why' parents make food choices for their children in a fast food restaurant environment, especially in terms of younger children (age $<6$ ) (McGuffin et al., 2015). There are even fewer studies that specifically examine pricing effects as a way of encouraging the selection of healthier fast food choices (Waterlander and Zenk, 2015).

Health-related taxes (e.g. fat and sugar taxes) that raise the price of food have been attempted as a policy instrument in a number of countries in an effort to encourage healthier food choices (Bødker et al., 2016; Smed et al., 2016)). Results to date have provided mixed outcomes. While there is some evidence that they encourage healthier eating, there is also evidence to suggest that the tax must be over $20 \%$ (Mytton et al., 2012) and that there can be unexpected and undesirable consequences of the tax such as increased consumption and unexpected substitution effects, which outweigh the beneficial effects on health outcomes (Bødker et al., 2015; Hanks et al., 2013; Maniadakis et al., 2013; Wansink et al., 2014). In addition, a 'fat tax' may well cost the poor more than the middle class (Muller et al., 2016).

In a recent study of the Danish 'fast food' sector (Lassen et al., 2016), looking at the aspect of adult healthier food choices and gender, results showed that irrespective of gender, the fast food customers indicated that they would like to see healthier menu items, however, only $7 \%$ of those surveyed picked healthier choices for themselves. This has also been observed in other studies (Gram and Blichfeldt, 2014; Yilmaz and Arslan, 2016). This leads to the question of how can fast food restaurants encourage consumers to select healthier choices for themselves and their children, when it may be a "do as I say not what I do" situation.

Price is often mentioned as a barrier in healthy food choices in general and thus, not surprisingly, there is less uptake if the price is higher for the healthier food item (Basch et al., 2013). When fast food restaurants offer healthier options at the same price, there is often a significant difference in the raw material cost for the healthier item and this can affect the restaurant's bottom line. Many fast food restaurants, such as McDonald's, Burger King, and Wendy's, offer healthier options as alternatives that can be substituted in a child's meal package at no price differential to the customer. However, despite this offer of a healthier option, at no additional price, the restaurants have frequently found that the uptake of these healthier choices for the child's meal package is minimal (Bleich et al., 2016).

In another recent study of intended fast food purchases, and one of the first randomized trials incorporating a sub-population of parents with children (Yoong et al., 2015), they found that just the provision of healthy items on a menu as an alternative was not enough to change parent purchasing behaviour as a strategy. They suggested that the price of the healthier item could be a potential reason for lack of selection.

The current pricing effect purchase intention study, using children's bundled fast food meals and healthier option substitutions, has been expanded upon to answer the following question: Is there $a$ difference in stated intent of what parents choose for their child's meal based on positive financial incentives to choose the healthier option versus a deterrent tax for choosing the unhealthy option? The healthier food option examined was the substitution of apple slices for french fries in children's meals at a hypothetical large national fast food restaurant in Canada. 


\section{Methods}

\subsection{Study Design}

The study was based on an online survey using Toluna Analytics, a commercial online survey platform, which provides access to a pool of participants who are representative of the Canadian population based on geography, household income, and education level. The survey was undertaken in three phases. Phase 1 examined stated intent of side dishestablished a baseline ordering and dessert orders for children's meals. pattern, and was used as a control group to establish if the tested pricing approaches shifted the percentage of what parents stated they would order for theirchild. Phase 2 tested an incentive approach to shifting side dish orders. Phase 3 tested a deterrent approach to shifting side dish orders.

A total of 400 respondents participated in the study. Respondents were not eligible to complete more than one phase of the research. The inclusion criteria included the following: Canadian resident, age 18 or above, equal numbers of males and females, the parent of a child that must currently live in the household. The average age of the respondent was 37.6 years. Households ranged in size from one to six children, with the majority of respondents having one child (53\%) or two children (34\%). Of the respondents, $68 \%$ were the primary grocery shopper for their household, $27 \%$ described themselves as sharing the grocery shopping responsibility with someone else, and $5 \%$ were not the primary grocery shopper (Appendix A -Demographic Questions).

For phase 1, 100 respondents were provided with a hypothetical scenario in which they were asked to consider that as a parent, if they took their own child to a large national fast-food restaurant and ordered a child's meal for their child, if there was no difference in price, whether they would order french fries or apple slices as the side dish for their child. The order of the side dishes was randomized to account for order bias (Appendix B $=$ - Side Dish and DessertBaseline Questions).

To further explore whether selecting a perceived healthier side dish for the child's meal resulted in any subsequent changes in ordering, the parent, after selecting the side dish for their child, was told that the restaurant chain offered a choice of desserts with the child meals. They were asked to choose between a small ice cream cone and an organic low fat yogurt (the perceived healthier option) for their child's dessert. Dessert options were randomized to account for order bias.

For phase 2, to investigate whether the provision of a discount as an incentive would change the stated intent of what a parent would order for their own child, 100 respondents were asked to review a scenario in which they imagined themselves with their own child at a large national fast food restaurant. In the scenario, they were provided with a financial discount if they choose the apple slices over french fries as the side dish in the child's meal and asked if the various financial discounts would shift their purchase decision. The discount options $(5,10,15,20,-25 \%)$ were described to the respondents both as a percentage of the price of the meal as well as a total dollar amount saved (Appendix C - Incentive Questions).

Example of Wording of One Scenario:

A large national fast food restaurant is interested in promoting healthy eating in children. Currently, they sell a child's meal for \$3.99. The typical child's meal contains a drink (milk or a small soft drink), an entrée (a cheeseburger, a hamburger or chicken nuggets) and a small side of french fries. While the restaurant currently offers apple slices as a substitute for french fries, they want to increase the number of parents that choose apple slices instead of french fries for their children. 
If you took your child to eat a child's meal at a fast food restaurant, which of the following options would change the type of side dish that you normally order for your child from french fries to apple slices?

A $5 \%$ price discount would convince me to change my child's order to apple slices instead of french fries (The child's meal would cost $\$ 3.79$, instead of $\$ 3.99$, saving you $\$ 0.20$ )

For phase 3, to investigate the up-charge (disincentive/ punitive) option, as before 100 respondents were asked to review the same restaurant scenario but were provided with a number of financial deterrents if they choose french fries over apple slices as the side dish in the child's meal. They were asked if various financial deterrents $(5,10,15,20,25 \%)$ would shift their purchase decision. The deterrent options were described as both as a percentage of the price of the meal, as well as a total dollar premium added to the price of the meal (Appendix D - Deterrents).

Another 100 respondents were given a slightly different question. As french fries are only a small portion of the child's meal, a specific question of an amount easy to visualize was used (i.e. a $\$ 0.25$ up-charge). The single deterrent question was phrased as "If you took your child to eat a child's meal at this fast food restaurant, would the $\$ 0.25$ up-charge for the fries change what you ordered?" (Appendix E - Deterrent - Price Specific).

\subsection{Statistical Analysis}

Statistical analysis using chi squared testing and ANOVA (SPSS Statistics, Version 22, IBM) compared the incentive approach to the deterrent approach to determine which pricing approach would have a greater impact on the percentage of parents that choose apple slices over french fries. In addition the parameters of gender, age, educational level and number of children in the household were examined to determine if these particular demographic characteristics had an influence on purchase behaviour.

\section{Results}

\subsection{Phase 1: Sides Dishes and Baseline Child's Meal Orders and Subsequent Dessert} Selection in Children's Meals

In the Phase 1 t study, with no financial penalty or incentive associated with the food side choice made for their child, $38 \%$ of parents stated they would ordered apple slices for their child and $62 \%$ stated they would ordered french fries.

A chi-squared test, with a statistically significant difference defined as $\mathrm{P}<0.05$, was performed to evaluate if the side dish item chosen by parents was influenced by the parental demographics. While most demographic subgroups demonstrated no difference in side selection for their child $_{L}$ (including gender ( $p=0.248)$, education level ( $p=0.928)$, ethnicity ( $p=0.472$ ), primary grocery shopper, household income $(p=0.438)$ and number of total children $(p=0.089))$, parents under the age of 35 years were statistically more likely to select apple slices as a side dish for their child than parents over the age of 35 years $(\mathrm{p}=0.034)$, at $p<0.05$ (Table 1$)$.

<insert Table 1 here>

Table 1. Side dish selected by parental age.

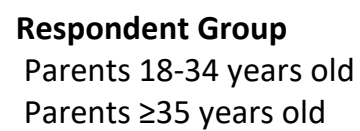

Apple Slices
$51 \%$
$27 \%$

French Fries
$49 \%$
$73 \%$ 
When parents were asked to choose between a small ice cream cone and an organic low fat yogurt (the perceived healthier option) for their child's dessert a chi-squared test indicated that the parents who chose french fries for the side dish for their child, chose the option of an ice cream cone more often than the low fat yogurt for their were statistically more likely to choose the option of an ice eream cone for their child's dessert $(p=0.010<0.05$ ) (Table 2 ). Similarly, parents who choose apple slices as the side dish, chose more likely to alsochoose the perceived healthier option of low fat yogurt as the dessert option more often than ice cream.

<insert Table 2 here >

Table 2. Chosen dessert item selected with apple or french fry side order.

$\begin{array}{ll}\text { \% of Respondents } & \text { Chosen Side and Dessert Combinations } \\ 42 \% & \text { French fries and ice cream cone } \\ 22 \% & \text { Apple slices and organic low-fat yogurt } \\ 20 \% & \text { French fries and organic low-fat yogurt } \\ 16 \% & \text { Apple slices and ice cream cone }\end{array}$

\subsection{Phase 2: Incentive Approach}

When asked whether the provision of a discount as an incentive would change the stated intent of what a parent would order for their own child, similar to the baseline-Phase 1 study, parents under the age of 35 were more likely to choose apple slices for their child, with $34 \%$ of parents $<35$ years of age responding that no financial incentive was required. They would already choose apple slices as a side dish for their child, while for parents over the age of 35 years, only $16 \%$ would choose apple slices as a side dish for their child with no financial incentive (Figure 1).

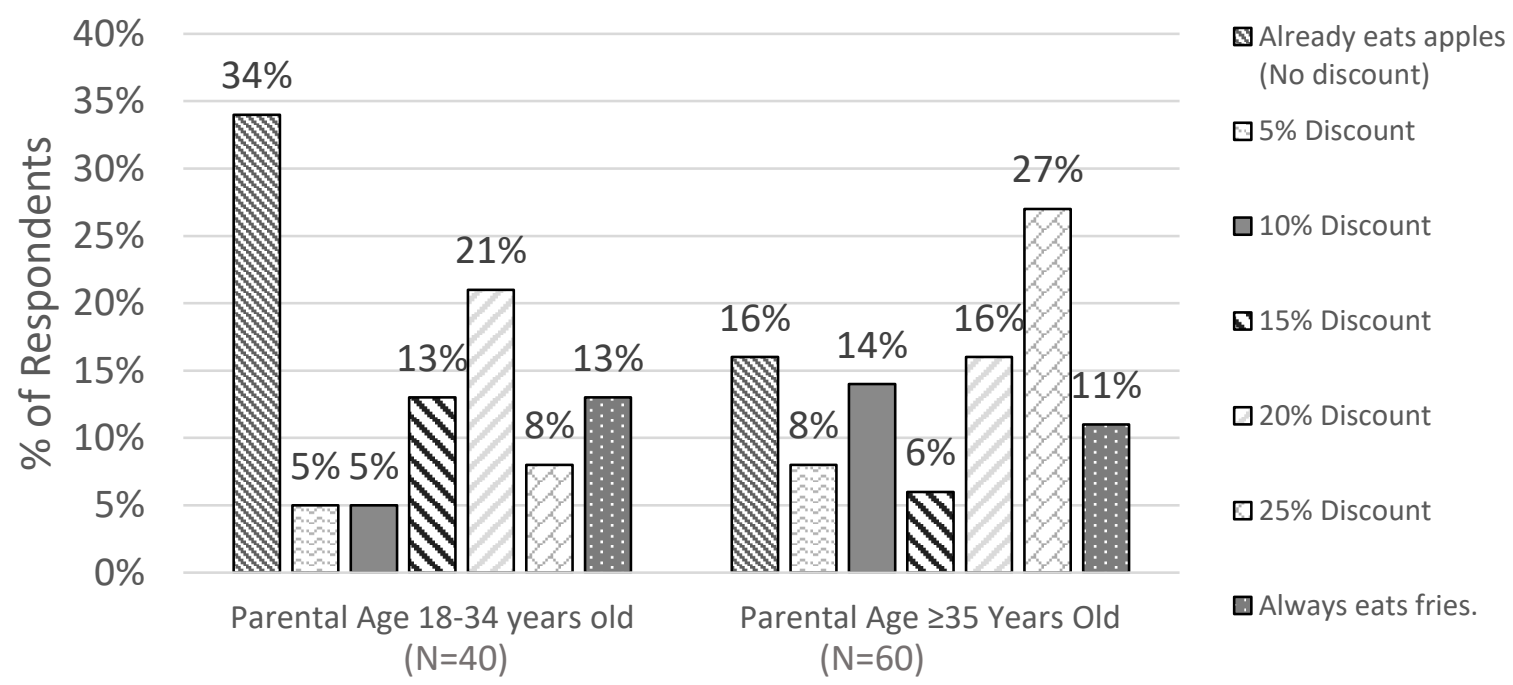

Figure 1. Incentive response to discount for healthier side option by age range, parental age 18-34 years and age $\geq 35$ years.

When the other demographics were examined using a chi squared test and ANOVA, no statistically significant difference was detected when examining respondent subgroups based on gender 
( $p=0.307)$, ethnicity ( $p=0.335)$, household income ( $p=0.779)$, education level ( $p=0.610)$, profession, number of children in the household $(p=0.753)$ or role as the primary grocery shopper $(p=0.746)$.

A $15 \%$ discount was required in order to persuade $50 \%$ of the population to have apple slices as their stated intended side dish that they would purchase for their own child. Table 3 shows the cumulative percentage of respondents that would choose apple slices over french fries based on the proposed financial discount. For example, a $10 \%$ discount on the overall price of the meal would result in $18 \%$ of the total respondents indicating that they would have normally chosen french fries as a side dish but would change their side dish choice to apple slices.

<insert Table 3 here >

Table 3. Cumulative percentage of respondents that would choose apple slices over french fries based on the proposed financial discount.

Proposed discount required for respondent to change their order from french fries into apple slices

\% Discount (Would order apple slices even if no discount was offered)

5\% Discount

$10 \%$ Discount

$15 \%$ Discount

$20 \%$ Discount

$25 \%$ Discount

Respondents would always order french fries
The \% of respondents that would select apple slices at the stated discount level

Cumulative \% of
respondents that would
select apple slices,
based on the escalating
discount level
$23 \%$

$23 \%$

$\begin{array}{cc}7 \% & 30 \% \\ 11 \% & 41 \%\end{array}$

$9 \% \quad 50 \%$

$18 \% \quad 68 \%$

$20 \% \quad 88 \%$

A discount of $\geq 15 \%$ on the overall meal price appears to be the financial incentive that would be required for half of the respondents to choose apple slices as the side dish for their child. On a \$3.99 child's meal, a $15 \%$ discount is a saving of $\$ 0.60$ (paying $\$ 3.39$ instead of $\$ 3.99$ for the meal).

\subsection{Phase 3: Deterrent Approach}

A graduated deterrent scale with 100 respondents showed that at a $5 \%$ up-charge $(\$ 0.20)$, there was already a $15 \%$ shift in the number of respondents that would select apple slices as a result of the up-charge (Appendix D - Table S1). Based on these results, another 100 respondents were surveyed using an up-charge of $\$ 0.25$, a practical amount to visualize in the context of fries and apple slices. As shown in Table 4, $36 \%$ of the respondents would avoid paying the additional $\$ 0.25$ up-charge, by choosing apple slices for their child when faced with a deterrent financial menu approach.

<insert Table 4 here>

Table 4. Distribution of responses to the deterrent pricing approach.

\section{Percent Responses}

14\% My child already eats apple slices instead of french fries as a part of their child's meal. The pricing change would not change what I would order.

$36 \% \quad$ A $\$ 0.25$ up-charge for french fries would change what I order for my child. I would rather order the apple slices for my child than pay the $\$ 0.25$ up-charge for french fries. 
A $\$ 0.25$ up-charge for french fries would NOT change what I order for my child. I would order the french fries for my child and I would pay the $\$ 0.25$ up-charge.

$13 \%$ I would always order french fries instead of apple slices for my child, regardless of the price.

An analysis of the demographic subgroups demonstrated no statistical differences in subgroup behaviour, including responses from parents based on the two age groups (i.e. $\geq 35$ years old and $<35$ years old).

\section{Discussion and Conclusions}

In Phase 1 of the study (baseline), french fries were the preferred side item chosen by parents for their child. Younger parents ( $<35$ years of age) were more likely to choose apple slices for their child and when given dessert options, parents who choose french fries as the side dish for their child were statistically more likely to choose ice cream as the dessert item. As younger parents were more likely to choose the healthier options for their child, this may be indicative of a difference in parenting styles of millennials. Millennial parents have demonstrated a difference in how concerned they are about other parents judging the food their children eat, more so than older generations (Steinmetz, 2015).

In Phase 2, the results from the financial incentive approach to shifting food choices suggest that a financial discount, rewarding healthier choices (apple slices instead of french fries), does have the potential to shift what parents order for their child. However, in order to reach half of the consumers intending to choose apple slices, a financial reward of at least a $15 \%$ discount on the overall meal price was required. While the introduction of a discount shifted 'stated' consumer behaviour, the $15 \%$ discount would likely be problematic to restaurants if the discount was applied to current meal prices. According to Statistics Canada (2014), the average limited-service eating place in Canada (comparable to the scenario described to respondents in the study), has less than a $6 \%$ operating profit margin, and full-service restaurants have an even smaller profit margin at less than $4 \%$. Implementing a financial discount as an incentive without raising the overall menu prices, would likely have such a detrimental impact on a restaurant's profit margin that it would be an unrealistic approach.

In Phase 3, the deterrent (punitive) pricing approach, while possibly a smaller percentage of the total cost of the child's meal, its introduction had a stronger per dollar influence on the decisions that the parents said that they would make. Regardless of the parent's age, the introduction of a $\$ 0.25$ up-charge for the choice of fries had a statistical impact on the side options chosen for the child, with half of the parents reporting that they would have their child eat apple slices rather than pay this premium. The $\$ 0.25$ up-charge was the equivalent of a $6 \%$ price increase on the proposed $\$ 3.99$ child's meal. This approach may be a more financially feasible option for a restaurantintroduced incentive to support healthier food decisions.

The deterrent pricing approach has similarities to the concept of 'fat taxes' that have been tried in other studies. In a study that examined sugared beverage purchase intentions for pre-school children, Ford et al. (2015) examined how a potential deterrent tax on sugar sweetened beverages (as well as high sugar milk and $>1 \%$ fat milk) might influence US consumers' beverage purchase decisions. They concluded that price increases from 10 to $20 \%$ might be associated with favourable effects in terms of reducing sugar purchases. Similar results on the potential use of deterrent pricing beyond beverages have been shown in this study. However, further research around the consumer 
response and acceptance of this approach would be required before implementing this at the restaurant level.

A limitation to this study is the potential inconsistency between purchase intent and actual behaviour. Examining 'stated' purchase intent only through the use of a questionnaire, and without a consequence of the choice, may not reflect a consumer's real purchase behaviour. This is an inherent limitation of using a communicative approach to collect data. Loureiro and Rahmani (2016) recently examined stated preference and actual choices in fast food choices and the limits in the stated predictions. In their study, which looked at the role that calorie information may have on fast food choices, while posted calories impacted stated intent, in field posted calorie information had a relatively low impact on actual behaviour. Henry and Borzekowski (2015) studied child fast food meal bundling and mothers' positive attitudes to the option of healthier food defaults in bundled meals. A future study should be conducted on pricing approaches in a restaurant setting, where the parents then have the consequences of interacting with their child and the child's response to the food decision made on their behalf.

The survey was also limited to a Canadian population and expanding the study to other countries may yield different results, although the reaction to the amount of "fat tax" required to change behaviour appears to be consistent over a number of countries where this implementation was tracked (Muller et al., 2016).

Despite the limitations, this study has produced some findings worthy of further investigation. The study suggests that pricing could be a possible tool to influence the food choices that parents make for their children. Attempts using a financial incentive approach were able to shift food choices away from french fries and into fresh fruit as a side dish, however the monetary incentive required ( $\geq 15 \%$ discount) would probably not be economically feasible from the perspective of the restaurant. While the deterrent (punitive) pricing approach to discourage less healthy choices may be more financially feasible from the perspective of the restaurant owner, the long term consumer perception and response to deterrent measures associated with choosing less healthy options requires further exploration. 


\section{References}

Anderson, K. and Mirosa, M. (2014), "Revealing barriers to healthier fast food consumption choices". British Food Journal, Vol. 116, No. 5, pp. 821-831.

Basch, C. H., Ethan, D. and Rajan, S. (2013), Price, promotion, and availability of nutrition information: A descriptive study of a popular fast food chain in New York City". Global Journal of Health Science, Vol. 5, No. 6, pp. $73-80$.

Bleich, S. N., Wolfson, J. A. and Jarlenski, M. P. (2016), "Calorie changes in large chain restaurants: Declines in new menu items but room for improvement". American Journal of Preventive Medicine, Vol. 50, No. 1, e1-e8.

Bødker, M., Pisinger, C., Toft, U. and Jørgensen, T. (2015), "The Danish fat tax-Effects on consumption patterns and risk of ischaemic heart disease". Preventive Medicine, Vol. 77, pp. 200-203.

Ford, C. N., Ng, S. W. and Popkin, B. M. (2015), "Targeted beverage taxes influence food and beverage purchases among households with preschool children". The Journal of Nutrition, Vol. 145 , No. 8, pp. 1835-1843.

Gram, M. and Blichfeldt, B. S. (2014), "When bad food happens to good intentions: Female students' food dilemmas". Journal of Youth Studies, Vol. 17, No.8, pp. 982-997.

Hanks, A., Wansink, B., Just, D., Smith, L., Cawley, J., Kaiser, H., Sobal, J., Wethington, E. and Schulze, W. (2013), "From Coke to Coors: A field study of a fat tax and its unintended consequences". Journal of Nutrition Education and Behavior, Vol. 4, No. 45, S40.

Henry, H. K. and Borzekowski, D. L. (2015), "Well, that's what came with it. A qualitative study of US mothers' perceptions of healthier default options for children's meals at fast-food restaurants". Appetite, Vol. 87, pp. 108-115.

Lassen, A. D., Lehmann, C., Andersen, E. W., Werther, M. N., Thorsen, A. V., Trolle, E., Gross, G., and Tetens, I. (2016), "Gender differences in purchase intentions and reasons for meal selection among fast food customers-Opportunities for healthier and more sustainable fast food". Food Quality and Preference, Vol. 47, pp. 123-129.

Loureiro, M. L. and Rahmani, D. (2016), "The incidence of calorie labeling on fast food choices: A comparison between stated preferences and actual choices". Economics \& Human Biology, Vol. 22, pp. 82-93.

Maniadakis, N., Kapaki, V., Damianidi, L. and Kourlaba, G. (2013), “A systematic review of the effectiveness of taxes on nonalcoholic beverages and high-in-fat foods as a means to prevent obesity trends". ClinicoEconomics and Outcomes Research, Vol. 5, pp. 519-543.

McGuffin, L. E., Price, R. K., McCaffrey, T. A., Hall, G., Lobo, A., Wallace, J. M. and Livingstone, M. B. E. (2015), "Parent and child perspectives on family out-of-home eating: a qualitative analysis". Public Health Nutrition, Vol. 18, No. 1, pp. 100-111.

Muller, L., Lacroix, A., Lusk, J. L. and Ruffieux, B. (2016), "Distributional impacts of fat taxes and thin subsidies". The Economic Journal, doi: 10.1111/ecoj.12357 
Mytton, O. T., Clarke, D. and Rayner, M. (2012), "Taxing unhealthy food and drinks to improve health". BMJ, Vol. 344, No. 7857, e2931.

Smed, S., Scarborough, P., Rayner, M. and Jensen, J. D. (2016), "The effects of the Danish saturated fat tax on food and nutrient intake and modelled health outcomes: an econometric and comparative risk assessment evaluation". European Journal of Clinical Nutrition. doi:10.1038/ejcn.2016.6

Statistics Canada (2014), "Food services and drinking places". available at: http://www.statcan.gc.ca/tables-tableaux/sum-som/l01/cst01/ (accessed 12 August 2016)

Steinmetz, K. (2015), “Help! My parents are millennials”. Time, Vol. 186 No. 17, pp. 36-43.

Wansink, B., Hanks, A. S. and Just, D. R. (2014), "From Coke to Coors: a field study of a fat tax and its unintended consequences". available at: http://conscienhealth.org/wpcontent/uploads/2014/05/ssrn-id2079840.pdf (accessed 12 August 2016)

Waterlander, W. E. and Zenk, S. N. (2015), "Food labelling, food retail availability and food pricing-moving from research to action?". Public Health Nutrition, Vol. 18, No. 1, pp. 2-7.

Yilmaz, A. and Arslan, Y. (2016), "A study to examine the health interest level of fast food consumers". International Journal of Social Sciences and Education Research, Vol. 2, No. 1, pp. 134-141.

Yoong, S. L., Dodds, P., Hure, A., Clinton-Mcharg, T., Skelton, E., Wiggers, J. and Wolfenden, L. (2015), "Healthier options do not reduce total energy of parent intended fast food purchases for their young children: a randomised controlled trial". Nutrition \& Dietetics. DOI: 10.1111/17470080.12204

\section{Appendix}

\section{Contents}

Appendix A: Demographic Questions Used In All Research Study Phases ..................................... 2

Appendix B: Baseline-Side Dish and Dessert Research Questions ................................................... 5

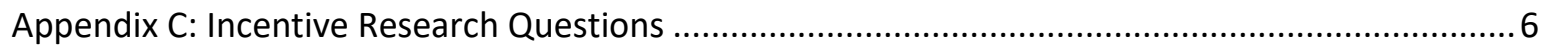

Appendix D: Deterrents (Deterrent Research Questions and Data) …......................................... 7

Appendix E: Deterrent - Price Specific …………….......................................................................... 


\section{Appendix A: Demographic Questions Used In All Research Study Phases}

1. Please select your country? (Extensive drop-down list of 253 countries provided)

a. Canada (English)

b. Country selected other than Canada (English) $\rightarrow$ survey discontinued.

2. Are you....?
a. Male
b. Female

3. Are you...?
a. Less than 18
b. $18-34$
c. $35-54$
d. $55 \%$

4. Region:
a. Western \& Northern Canada
b. Ontario
c. Quebec
d. Atlantic Canada

5. Origin
a. North American Aboriginal origins
b. Other North American origins
c. British Isles origins
d. French origins
e. Western European origins (except French origins)
f. Northern European origins (except British Isles origins)
g. Eastern European origins
h. Southern European origins
i. Other European origins
j. Caribbean origins
k. Latin, Central and South American origins
I. Central and West African origins
m. North African origins
n. Southern and East African origins
o. Other African origins
p. West Central Asian and Middle Eastern origins
q. South Asian origins
r. East and Southeast Asian origins
s. Other Asian origins
t. Oceania origins
u. Not sure/Prefer not to say

6. What is your education level?
a. Elementary school
b. Middle school/junior high
c. High school
d. Some college/university
e. Graduated 2-year college 
f. Graduated 4-year college/university

g. Graduate school

h. Postgraduate

i. Prefer not to say

7. What is you annual household income?

a. Under $\$ 15,000$

b. $\$ 15,000-\$ 19,999$

c. $\$ 20,000-\$ 24,999$

d. $\$ 25,000-\$ 29,999$

e. $\$ 30,000-\$ 34,999$

f. $\$ 35,000-\$ 39,999$

g. $\$ 40,000-\$ 44,999$

h. $\$ 45,000-\$ 49,999$

i. $\$ 50,000-\$ 54,999$

j. $\$ 55,000-\$ 59,999$

k. $\$ 60,000-\$ 64,999$

I. $\$ 65,000-\$ 69,999$

m. $\$ 70,000-\$ 74,999$

n. $\$ 75,000-\$ 79,999$

o. $\$ 80,000-\$ 84,999$

p. $\$ 85,000-\$ 89,999$

q. $\$ 90,000-\$ 94,999$

r. $\$ 95,000-\$ 99,999$

s. $\$ 100,000-\$ 124,999$

t. $\$ 125,000-\$ 149,999$

u. $\$ 125,000-\$ 149,999$

v. $\$ 200,000+$

8. Employment
a. High managerial, administrative or professional
b. Intermediate managerial, administrative or professional
c. Supervisor; clerical; junior managerial, administrative or professional
d. Intellectual profession, Executive, Freelance
e. Intermediate profession: Public sector ( health, teaching...) companies
f. Intermediate Professional Liberal Profession
g. Farmer ( farm owner)
h. Craftman, shop owner, managing director
i. Employee, public sector companies
j. Skilled manual worker
k. Semi-skilled or unskilled manual worker
I. Housewife / Homemaker
m. Retired
n. Student

o. Unemployed

9. Are you the primary grocery shopper for your household?
a. Yes
b. No
c. Share responsibility 
10. Number of children under 18 in your household:
a. 0
b. 1
c. 2
d. 3
e. 4
f. 5
g. 6
h. 7
i. 8
j. 9
k. $10+$

11. Number of people in your household including you:
a. 1
b. 2
c. 3
d. 4
e. 5
f. 6
g. 7
h. 8
i. 9
j. $10+$ 


\title{
Appendix B: Baseline Side Dish and Dessert Research Questions
}

\begin{abstract}
A large national fast food restaurant is interested in promoting healthy eating in children. Currently, they sell a child's meal for \$3.99. The typical child's meal contains a drink (milk or a small soft drink), an entrée (a cheeseburger, a hamburger or chicken nuggets) and a side (apple slices or french fries). If you took your child to eat a child's meal at this large national fast food restaurant, which side would you most likely choose for your child?
\end{abstract}
Apple Slices
French Fries

The large national fast food restaurant mentioned in the previous question, is planning it expand the child's meal to include a dessert item. If you took your child to eat a child's meal at this national fast food restaurant, which dessert item would you most likely choose for your child?

Organic Low Fat Yogurt

Small Ice Cream Cone 
A large national fast food restaurant is interested in promoting healthy eating in children. Currently, they sell a child's meal for \$3.99. The typical child's meal contains a drink (milk or a small soft drink), an entrée (a cheeseburger, a hamburger or chicken nuggets) and a small side of french fries. While the restaurant currently offers apple slices as a substitute for french fries, they want to increase the number of parents that choose apple slices instead of french fries for their children.

If you took your child to eat a child's meal at a fast food restaurant, which of the following options would change the type of side dish that you normally order for your child from french fries to apple slices?

My child already eats apple slices instead of french fries, as a part of their child's meal. A $5 \%$ price discount would convince me to change my child's order to apple slices instead of french fries (The child's meal would cost $\$ 3.79$, instead of $\$ 3.99$, saving you $\$ 0.20$ ) A $10 \%$ price discount would convince me to change my child's order to apple slices instead of french fries (The child's meal would cost $\$ 3.59$, instead of $\$ 3.99$, saving you $\$ 0.40$ ) A $15 \%$ price discount would convince me to change my child's order to apple slices instead of french fries (The child's meal would cost $\$ 3.39$, instead of $\$ 3.99$, saving you $\$ 0.60$ )

A $20 \%$ price discount would convince me to change my child's order to apple slices instead of french fries (The child's meal would cost $\$ 3.19$, instead of $\$ 3.99$, saving you $\$ 0.80$ )

A $25 \%$ price discount would convince me to change my child's order to apple slices instead of french fries (The child's meal would cost $\$ 2.99$, instead of $\$ 3.99$, saving you $\$ 1.00$ )

I would always order french fries instead of apple slices for my child. No discount in the price of the meal would change my mind. 


\section{Appendix D: Deterrents (Deterrent Research Questions and Data)}

A large national fast food restaurant is interested in promoting healthy eating in children.

Currently, they sell a child's meal for \$3.99. The typical child's meal contains a drink (milk or a small soft drink), an entrée (a cheeseburger, a hamburger or chicken nuggets) and a small side of french fries.

While the restaurant currently offers apple slices as a substitute for french fries, they want to increase the number of parents that choose apple slices instead of french fries for their children. To encourage parents to choose apple slices instead of french fries for their children, the restaurant is planning to add an up-charge if french fries are chosen as a part of the child's meal.

The new menu pricing will be:

\$3.99 for a child's meal with a drink, an entree and apple slices +an up-charge to substitute french fries instead of apple slices.

If you took your child to eat a child's meal at a fast food restaurant, which of the following options would change the type of side dish that you normally order for your child from French Fries to Apple Slices.

My child already eats apple slices instead of french fries, as a part of their child's meal.

A 5\% up-charge would convince me to change my child's order to apple slices instead of French Fries (The child's meal would cost $\$ 4.19$, instead of $\$ 3.99$, charging you an additional $\$ 0.20$ for substituting french fries instead of apple slices)

A 10\% up-charge would convince me to change my child's order to apple slices instead of French Fries (The child's meal would cost $\$ 4.39$, instead of $\$ 3.99$, charging you an additional $\$ 0.40$ for substituting french fries instead of apple slices)

A 15\% up-charge would convince me to change my child's order to apple slices instead of French Fries (The child's meal would cost $\$ 4.59$, instead of $\$ 3.99$, charging you an additional $\$ 0.60$ for substituting french fries instead of apple slices)

A 20\% up-charge would convince me to change my child's order to apple slices instead of French Fries (The child's meal would cost $\$ 4.79$, instead of $\$ 3.99$, charging you an additional $\$ 0.80$ for substituting french fries instead of apple slices)

A $25 \%$ up-charge would convince me to change my child's order to apple slices instead of French Fries (The child's meal would cost $\$ 4.99$, instead of $\$ 3.99$, charging you an additional $\$ 1.00$ for substituting french fries instead of apple slices)

I would always order French fries instead of apple slices for my child, regardless of the price.

Table S1 - Cumulative percentage of respondents that would choose apple slices over french fries based on the proposed financial deterrent. Proposed-up-charge for french fries required for respondents to
change their order to apple slices

$0 \%$ Deterrent (Would order apple slices even if there was no pricing deterrent)

$5 \%$ Deterrent (\$0.20 up-charge)

$10 \%$ Deterrent $(\$ 0.40$ up-charge)

$15 \%$ Deterrent $(\$ 0.50$ up-charge)

$20 \%$ Deterrent (\$0.80 up-charge)

$25 \%$ Deterrent (\$1.00 up-charge)

Respondents would always order french fries
Percent of respondents that would select apple slices at the stated deterrent up-charge level for fries

$18 \%$

$15 \%$

$11 \%$

$14 \%$

$16 \%$

$13 \%$

$13 \%$
Cumulative $\%$ of respondents that would order apple slices, based on the escalating deterrent up-charge level for fries

$18 \%$

$33 \%$

$44 \%$

$58 \%$

$74 \%$

$87 \%$ 


\section{Appendix E: Deterrent Question - Price Specific}

A large national fast food restaurant is interested in promoting healthy eating in children. Currently, they sell a child's meal for \$3.99. The typical child's meal contains a drink (milk or a small soft drink), an entrée (a cheeseburger, a hamburger or chicken nuggets) and a small side of french fries. While the restaurant currently offers apple slices as a substitute for french fries, they want to increase the number of parents that choose apple slices instead of french fries for their children. To encourage parents to choose apple slices instead of french fries for their children, the restaurant is planning to charge an additional $\$ 0.25$ if french fries are chosen as a part of the child's meal. The new menu pricing will be: $\$ 3.99$ for a child's meal with a drink, an entree and apple slices $+\$ 0.25$ to substitute french fries instead of apple slices.

If you took your child to eat a child's meal at this fast food restaurant, would the $\$ 0.25$ up-charge for french fries change what you ordered for your child?

My child already eats apple slices instead of french fries as a part of their child's meal. The pricing change would not change our order.

A $\$ 0.25$ up-charge for french fries would change what I order for my child. I would rather order the apple slices for my child than pay the $\$ 0.25$ up-charge for french fries.

A $\$ 0.25$ up-charge for french fries would NOT change what I order for my child. I would order the french fries for my child and I would pay the $\$ 0.25$ up-charge.

I would always order french fries instead of apple slices for my child, regardless of the price. 


\section{Structured Abstract}

Purpose - This study investigated the use of pricing (incentive and deterrent) to shift the purchase decision intent of parents when they order food for their child in a fast food restaurant.

Design/methodology/approach- A financial incentive and a deterrent pricing tactic was tested using an online, quantitative approach with a sample of 400 Canadian parents, representative of the Canadian population based on geography, household income, and education level.

Findings- The financial incentive tactic demonstrated that a strong and clearly articulated monetary discount can shift the stated purchase intent of parents into an increased number choosing a healthier side dish for a child's fast food meal. A deterrent pricing approach was shown to also shift stated purchase intent, and had a higher consumer impact on a per dollar basis. Younger parents ( $<35$ years old) were more likely to select healthier side dishes for their child, however, parents of all ages could potentially be influenced through motivational pricing approaches.

Research limitations/implications This was an exploratory study using online surveys and stated purchase intent among Canadian respondents. Examining 'stated' purchase intent only through the use of a questionnaire, and without a consequence of the choice, may not reflect a consumer's real purchase behaviour. A future study should be conducted on pricing approaches in a restaurant setting, where the parents then have the consequences of interacting with the child and the response of the child to the food decision made on their behalf.

Practical implications The use of pricing to shift parental food purchase decisions into ordering healthier food items for their children is a promising option, which with further exploration may lead to easily implementable restaurant-level recommendations that achieve the desired results of children eating healthier.

Social implications As the frequency of fast food consumption continues to rise, encouraging healthier fast food choices for children could help to combat the troubling rise of obesity in young children.

Originality/value: While most historical research has focused on teen or adult consumers, this paper offers insights to academics, marketers and restaurant industry influencers into the previously unexplored area of using pricing to encourage parents to make healthier food choices for children in a fast food restaurant environment.

Keywords Children, Disincentive, Fast-food, Food-choice, Health, Incentive, Parents, Pricing, Restaurant.

\section{Paper Type Research Paper}




\section{Introduction}

Food choice can impact health and with the rapidly rising number of meals eaten at fast food restaurants by children there is concern regarding the effects of less healthy food choices (Anderson and Mirosa, 2014). There is a general lack of data on 'how and why' parents make food choices for their children in a fast food restaurant environment, especially in terms of younger children (age $<6$ ) (McGuffin et al., 2015). There are even fewer studies that specifically examine pricing effects as a way of encouraging the selection of healthier fast food choices (Waterlander and Zenk, 2015).

Health-related taxes (e.g. fat and sugar taxes) that raise the price of food have been attempted as a policy instrument in a number of countries in an effort to encourage healthier food choices (Bødker et al., 2016; Smed et al., 2016)). Results to date have provided mixed outcomes. While there is some evidence that they encourage healthier eating, there is also evidence to suggest that the tax must be over $20 \%$ (Mytton et al., 2012) and that there can be unexpected and undesirable consequences of the tax such as increased consumption and unexpected substitution effects, which outweigh the beneficial effects on health outcomes (Bødker et al., 2015; Hanks et al., 2013; Maniadakis et al., 2013; Wansink et al., 2014). In addition, a 'fat tax' may well cost the poor more than the middle class (Muller et al., 2016).

In a recent study of the Danish 'fast food' sector (Lassen et al., 2016), looking at the aspect of adult healthier food choices and gender, results showed that irrespective of gender, the fast food customers indicated that they would like to see healthier menu items, however, only $7 \%$ of those surveyed picked healthier choices for themselves. This has also been observed in other studies (Gram and Blichfeldt, 2014; Yilmaz and Arslan, 2016). This leads to the question of how can fast food restaurants encourage consumers to select healthier choices for themselves and their children, when it may be a "do as I say not what I do" situation.

Price is often mentioned as a barrier in healthy food choices in general and thus, not surprisingly, there is less uptake if the price is higher for the healthier food item (Basch et al., 2013). When fast food restaurants offer healthier options at the same price, there is often a significant difference in the raw material cost for the healthier item and this can affect the restaurant's bottom line. Many fast food restaurants, such as McDonald's, Burger King, and Wendy's, offer healthier options as alternatives that can be substituted in a child's meal package at no price differential to the customer. However, despite this offer of a healthier option, at no additional price, the restaurants have frequently found that the uptake of these healthier choices for the child's meal package is minimal (Bleich et al., 2016).

In another recent study of intended fast food purchases, and one of the first randomized trials incorporating a sub-population of parents with children (Yoong et al., 2015), they found that just the provision of healthy items on a menu as an alternative was not enough to change parent purchasing behaviour as a strategy. They suggested that the price of the healthier item could be a potential reason for lack of selection.

The current pricing effect purchase intention study, using children's bundled fast food meals and healthier option substitutions, has been expanded upon to answer the following question: Is there $a$ difference in stated intent of what parents choose for their child's meal based on positive financial incentives to choose the healthier option versus a deterrent tax for choosing the unhealthy option? The healthier food option examined was the substitution of apple slices for french fries in children's meals at a hypothetical large national fast food restaurant in Canada. 


\section{Methods}

\subsection{Study Design}

The study was based on an online survey using Toluna Analytics, a commercial online survey platform, which provides access to a pool of participants who are representative of the Canadian population based on geography, household income, and education level. The survey was undertaken in three phases. Phase 1 examined stated intent of side dish ordering and dessert orders for children's meals. Phase 2 tested an incentive approach to shifting side dish orders. Phase 3 tested a deterrent approach to shifting side dish orders.

A total of 400 respondents participated in the study. Respondents were not eligible to complete more than one phase of the research. The inclusion criteria included the following: Canadian resident, age 18 or above, equal numbers of males and females, the parent of a child that must currently live in the household. The average age of the respondent was 37.6 years. Households ranged in size from one to six children, with the majority of respondents having one child (53\%) or two children (34\%). Of the respondents, $68 \%$ were the primary grocery shopper for their household, $27 \%$ described themselves as sharing the grocery shopping responsibility with someone else, and $5 \%$ were not the primary grocery shopper (Appendix A -Demographic Questions).

For phase 1, 100 respondents were provided with a hypothetical scenario in which they were asked to consider that as a parent, if they took their own child to a large national fast-food restaurant and ordered a child's meal for their child, if there was no difference in price, whether they would order french fries or apple slices as the side dish for their child. The order of the side dishes was randomized to account for order bias (Appendix B - Side Dish and Dessert Questions).

To further explore whether selecting a perceived healthier side dish for the child's meal resulted in any subsequent changes in ordering, the parent, after selecting the side dish for their child, was told that the restaurant chain offered a choice of desserts with the child meals. They were asked to choose between a small ice cream cone and an organic low fat yogurt (the perceived healthier option) for their child's dessert. Dessert options were randomized to account for order bias.

For phase 2, to investigate whether the provision of a discount as an incentive would change the stated intent of what a parent would order for their own child, 100 respondents were asked to review a scenario in which they imagined themselves with their own child at a large national fast food restaurant. In the scenario, they were provided with a financial discount if they choose the apple slices over french fries as the side dish in the child's meal and asked if the various financial discounts would shift their purchase decision. The discount options $(5,10,15,20,25 \%)$ were described to the respondents both as a percentage of the price of the meal as well as a total dollar amount saved (Appendix C - Incentive Questions).

Example of Wording of One Scenario:

A large national fast food restaurant is interested in promoting healthy eating in children. Currently, they sell a child's meal for \$3.99. The typical child's meal contains a drink (milk or a small soft drink), an entrée (a cheeseburger, a hamburger or chicken nuggets) and a small side of french fries. While the restaurant currently offers apple slices as a substitute for french fries, they want to increase the number of parents that choose apple slices instead of french fries for their children. 
If you took your child to eat a child's meal at a fast food restaurant, which of the following options would change the type of side dish that you normally order for your child from french fries to apple slices?

A $5 \%$ price discount would convince me to change my child's order to apple slices instead of french fries (The child's meal would cost $\$ 3.79$, instead of $\$ 3.99$, saving you $\$ 0.20$ )

For phase 3, to investigate the up-charge (disincentive/ punitive) option, as before 100 respondents were asked to review the same restaurant scenario but were provided with a number of financial deterrents if they choose french fries over apple slices as the side dish in the child's meal. They were asked if various financial deterrents $(5,10,15,20,25 \%)$ would shift their purchase decision. The deterrent options were described as both as a percentage of the price of the meal, as well as a total dollar premium added to the price of the meal (Appendix D - Deterrents).

Another 100 respondents were given a slightly different question. As french fries are only a small portion of the child's meal, a specific question of an amount easy to visualize was used (i.e. a $\$ 0.25$ up-charge). The single deterrent question was phrased as "If you took your child to eat a child's meal at this fast food restaurant, would the $\$ 0.25$ up-charge for the fries change what you ordered?" (Appendix E - Deterrent - Price Specific).

\subsection{Statistical Analysis}

Statistical analysis using chi squared testing and ANOVA (SPSS Statistics, Version 22, IBM) compared the incentive approach to the deterrent approach to determine which pricing approach would have a greater impact on the percentage of parents that choose apple slices over french fries. In addition the parameters of gender, age, educational level and number of children in the household were examined to determine if these particular demographic characteristics had an influence on purchase behaviour.

\section{Results}

\subsection{Phase 1: Sides Dishes and Subsequent Dessert Selection in Children's Meals}

In the Phase 1 study, with no financial penalty or incentive associated with the food side choice made for their child, $38 \%$ of parents stated they would order apple slices for their child and $62 \%$ stated they would order french fries.

A chi-squared test, with a statistically significant difference defined as $\mathrm{P}<0.05$, was performed to evaluate if the side dish item chosen by parents was influenced by the parental demographics. While most demographic subgroups demonstrated no difference in side selection for their child, (including gender $(p=0.248)$, education level $(p=0.928)$, ethnicity $(p=0.472)$, household income $(p=0.438)$ and number of total children $(p=0.089)$ ), parents under the age of 35 years were statistically more likely to select apple slices as a side dish for their child than parents over the age of 35 years $(p=0.034)$, at $\mathrm{p}<0.05$ (Table 1).

When parents were asked to choose between a small ice cream cone and an organic low fat yogurt (the perceived healthier option) for their child's dessert a chi-squared test indicated that the parents who chose french fries for the side dish for their child, chose the option of an ice cream cone more often than the low-fat yogurt for their child's dessert ( $p=0.010$ ) (Table 2). Similarly, parents who choose apple slices as the side dish, chose the perceived healthier option of low fat yogurt as the dessert option more often than ice cream. 


\subsection{Phase 2: Incentive Approach}

When asked whether the provision of a discount as an incentive would change the stated intent of what a parent would order for their own child, similar to the Phase 1 study, parents under the age of 35 were more likely to choose apple slices for their child, with $34 \%$ of parents $<35$ years of age responding that no financial incentive was required. They would already choose apple slices as a side dish for their child, while for parents over the age of 35 years, only $16 \%$ would choose apple slices as a side dish for their child with no financial incentive (Figure 1).

When the other demographics were examined using a chi squared test and ANOVA, no statistically significant difference was detected when examining respondent subgroups based on gender $(p=0.307)$, ethnicity $(p=0.335)$, household income $(p=0.779)$, education level $(p=0.610)$, number of children in the household $(p=0.753)$ or role as the primary grocery shopper $(p=0.746)$.

A $15 \%$ discount was required in order to persuade $50 \%$ of the population to have apple slices as their stated intended side dish that they would purchase for their own child. Table 3 shows the cumulative percentage of respondents that would choose apple slices over french fries based on the proposed financial discount. For example, a $10 \%$ discount on the overall price of the meal would result in $18 \%$ of the total respondents indicating that they would have normally chosen french fries as a side dish but would change their side dish choice to apple slices.

A discount of $\geq 15 \%$ on the overall meal price appears to be the financial incentive that would be required for half of the respondents to choose apple slices as the side dish for their child. On a $\$ 3.99$ child's meal, a $15 \%$ discount is a saving of $\$ 0.60$ (paying $\$ 3.39$ instead of $\$ 3.99$ for the meal).

\subsection{Phase 3: Deterrent Approach}

A graduated deterrent scale with 100 respondents showed that at a $5 \%$ up-charge $(\$ 0.20)$, there was already a $15 \%$ shift in the number of respondents that would select apple slices as a result of the up-charge (Appendix D - Table S1). Based on these results, another 100 respondents were surveyed using an up-charge of $\$ 0.25$, a practical amount to visualize in the context of fries and apple slices. As shown in Table 4, $36 \%$ of the respondents would avoid paying the additional $\$ 0.25$ up-charge, by choosing apple slices for their child when faced with a deterrent financial menu approach.

An analysis of the demographic subgroups demonstrated no statistical differences in subgroup behaviour, including responses from parents based on the two age groups (i.e. $\geq 35$ years old and $<35$ years old).

\section{Discussion and Conclusions}

In Phase 1 of the study, french fries were the preferred side item chosen by parents for their child. Younger parents ( $<35$ years of age) were more likely to choose apple slices for their child and when given dessert options, parents who choose french fries as the side dish for their child were statistically more likely to choose ice cream as the dessert item. As younger parents were more likely to choose the healthier options for their child, this may be indicative of a difference in parenting styles of millennials. Millennial parents have demonstrated a difference in how concerned they are about other parents judging the food their children eat, more so than older generations (Steinmetz, 2015).

In Phase 2, the results from the financial incentive approach to shifting food choices suggest that a financial discount, rewarding healthier choices (apple slices instead of french fries), does have the potential to shift what parents order for their child. However, in order to reach half of the 
consumers intending to choose apple slices, a financial reward of at least a $15 \%$ discount on the overall meal price was required. While the introduction of a discount shifted 'stated' consumer behaviour, the $15 \%$ discount would likely be problematic to restaurants if the discount was applied to current meal prices. According to Statistics Canada (2014), the average limited-service eating place in Canada (comparable to the scenario described to respondents in the study), has less than a $6 \%$ operating profit margin, and full-service restaurants have an even smaller profit margin at less than $4 \%$. Implementing a financial discount as an incentive without raising the overall menu prices, would likely have such a detrimental impact on a restaurant's profit margin that it would be an unrealistic approach.

In Phase 3, the deterrent (punitive) pricing approach, while possibly a smaller percentage of the total cost of the child's meal, its introduction had a stronger per dollar influence on the decisions that the parents said that they would make. Regardless of the parent's age, the introduction of a \$0.25 up-charge for the choice of fries had a statistical impact on the side options chosen for the child, with half of the parents reporting that they would have their child eat apple slices rather than pay this premium. The $\$ 0.25$ up-charge was the equivalent of a $6 \%$ price increase on the proposed $\$ 3.99$ child's meal. This approach may be a more financially feasible option for a restaurantintroduced incentive to support healthier food decisions.

The deterrent pricing approach has similarities to the concept of 'fat taxes' that have been tried in other studies. In a study that examined sugared beverage purchase intentions for pre-school children, Ford et al. (2015) examined how a potential deterrent tax on sugar sweetened beverages (as well as high sugar milk and $>1 \%$ fat milk) might influence US consumers' beverage purchase decisions. They concluded that price increases from 10 to $20 \%$ might be associated with favourable effects in terms of reducing sugar purchases. Similar results on the potential use of deterrent pricing beyond beverages have been shown in this study. However, further research around the consumer response and acceptance of this approach would be required before implementing this at the restaurant level.

A limitation to this study is the potential inconsistency between purchase intent and actual behaviour. Examining 'stated' purchase intent only through the use of a questionnaire, and without a consequence of the choice, may not reflect a consumer's real purchase behaviour. This is an inherent limitation of using a communicative approach to collect data. Loureiro and Rahmani (2016) recently examined stated preference and actual choices in fast food choices and the limits in the stated predictions. In their study, which looked at the role that calorie information may have on fast food choices, while posted calories impacted stated intent, in field posted calorie information had a relatively low impact on actual behaviour. Henry and Borzekowski (2015) studied child fast food meal bundling and mothers' positive attitudes to the option of healthier food defaults in bundled meals. A future study should be conducted on pricing approaches in a restaurant setting, where the parents then have the consequences of interacting with their child and the child's response to the food decision made on their behalf.

The survey was also limited to a Canadian population and expanding the study to other countries may yield different results, although the reaction to the amount of "fat tax" required to change behaviour appears to be consistent over a number of countries where this implementation was tracked (Muller et al., 2016).

Despite the limitations, this study has produced some findings worthy of further investigation. The study suggests that pricing could be a possible tool to influence the food choices that parents make for their children. Attempts using a financial incentive approach were able to shift food choices 
away from french fries and into fresh fruit as a side dish, however the monetary incentive required ( $\geq 15 \%$ discount) would probably not be economically feasible from the perspective of the restaurant. While the deterrent (punitive) pricing approach to discourage less healthy choices may be more financially feasible from the perspective of the restaurant owner, the long term consumer perception and response to deterrent measures associated with choosing less healthy options requires further exploration. 


\section{References}

Anderson, K. and Mirosa, M. (2014), "Revealing barriers to healthier fast food consumption choices". British Food Journal, Vol. 116, No. 5, pp. 821-831.

Basch, C. H., Ethan, D. and Rajan, S. (2013), Price, promotion, and availability of nutrition information: A descriptive study of a popular fast food chain in New York City". Global Journal of Health Science, Vol. 5, No. 6, pp. $73-80$.

Bleich, S. N., Wolfson, J. A. and Jarlenski, M. P. (2016), "Calorie changes in large chain restaurants: Declines in new menu items but room for improvement". American Journal of Preventive Medicine, Vol. 50, No. 1, e1-e8.

Bødker, M., Pisinger, C., Toft, U. and Jørgensen, T. (2015), "The Danish fat tax-Effects on consumption patterns and risk of ischaemic heart disease". Preventive Medicine, Vol. 77, pp. 200-203.

Ford, C. N., Ng, S. W. and Popkin, B. M. (2015), "Targeted beverage taxes influence food and beverage purchases among households with preschool children". The Journal of Nutrition, Vol. 145 , No. 8 , pp. $1835-1843$.

Gram, M. and Blichfeldt, B. S. (2014), "When bad food happens to good intentions: Female students' food dilemmas". Journal of Youth Studies, Vol. 17, No.8, pp. 982-997.

Hanks, A., Wansink, B., Just, D., Smith, L., Cawley, J., Kaiser, H., Sobal, J., Wethington, E. and Schulze, W. (2013), "From Coke to Coors: A field study of a fat tax and its unintended consequences". Journal of Nutrition Education and Behavior, Vol. 4, No. 45, S40.

Henry, H. K. and Borzekowski, D. L. (2015), "Well, that's what came with it. A qualitative study of US mothers' perceptions of healthier default options for children's meals at fast-food restaurants". Appetite, Vol. 87, pp. 108-115.

Lassen, A. D., Lehmann, C., Andersen, E. W., Werther, M. N., Thorsen, A. V., Trolle, E., Gross, G., and Tetens, I. (2016), "Gender differences in purchase intentions and reasons for meal selection among fast food customers-Opportunities for healthier and more sustainable fast food". Food Quality and Preference, Vol. 47, pp. 123-129.

Loureiro, M. L. and Rahmani, D. (2016), "The incidence of calorie labeling on fast food choices: A comparison between stated preferences and actual choices". Economics \& Human Biology, Vol. 22, pp. 82-93.

Maniadakis, N., Kapaki, V., Damianidi, L. and Kourlaba, G. (2013), "A systematic review of the effectiveness of taxes on nonalcoholic beverages and high-in-fat foods as a means to prevent obesity trends". ClinicoEconomics and Outcomes Research, Vol. 5, pp. 519-543.

McGuffin, L. E., Price, R. K., McCaffrey, T. A., Hall, G., Lobo, A., Wallace, J. M. and Livingstone, M. B. E. (2015), "Parent and child perspectives on family out-of-home eating: a qualitative analysis". Public Health Nutrition, Vol. 18, No. 1, pp. 100-111.

Muller, L., Lacroix, A., Lusk, J. L. and Ruffieux, B. (2016), "Distributional impacts of fat taxes and thin subsidies". The Economic Journal, doi: 10.1111/ecoj.12357 
Mytton, O. T., Clarke, D. and Rayner, M. (2012), "Taxing unhealthy food and drinks to improve health". BMJ, Vol. 344, No. 7857, e2931.

Smed, S., Scarborough, P., Rayner, M. and Jensen, J. D. (2016), "The effects of the Danish saturated fat tax on food and nutrient intake and modelled health outcomes: an econometric and comparative risk assessment evaluation". European Journal of Clinical Nutrition. doi:10.1038/ejcn.2016.6

Statistics Canada (2014), "Food services and drinking places". available at: http://www.statcan.gc.ca/tables-tableaux/sum-som/l01/cst01/ (accessed 12 August 2016)

Steinmetz, K. (2015), “Help! My parents are millennials”. Time, Vol. 186 No. 17, pp. 36-43.

Wansink, B., Hanks, A. S. and Just, D. R. (2014), "From Coke to Coors: a field study of a fat tax and its unintended consequences". available at: http://conscienhealth.org/wp-

content/uploads/2014/05/ssrn-id2079840.pdf (accessed 12 August 2016)

Waterlander, W. E. and Zenk, S. N. (2015), "Food labelling, food retail availability and food pricing-moving from research to action?". Public Health Nutrition, Vol. 18, No. 1, pp. 2-7.

Yilmaz, A. and Arslan, Y. (2016), "A study to examine the health interest level of fast food consumers". International Journal of Social Sciences and Education Research, Vol. 2, No. 1, pp. 134-141.

Yoong, S. L., Dodds, P., Hure, A., Clinton-Mcharg, T., Skelton, E., Wiggers, J. and Wolfenden, L. (2015), "Healthier options do not reduce total energy of parent intended fast food purchases for their young children: a randomised controlled trial". Nutrition \& Dietetics. DOI: 10.1111/17470080.12204 


\section{Appendix}

\section{Contents}

Appendix A: Demographic Questions Used In All Research Study Phases ...................................... 2

Appendix B: Side Dish and Dessert Research Questions ............................................................ 5

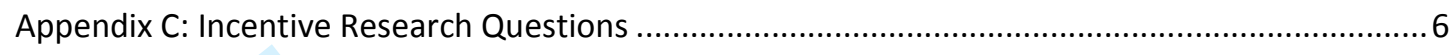

Appendix D: Deterrents (Deterrent Research Questions and Data) ..............................................

Appendix E: Deterrent - Price Specific …………........................................................................ 


\section{Appendix A: Demographic Questions Used In All Research Study Phases}

1. Please select your country? (Extensive drop-down list of 253 countries provided)

a. Canada (English)

b. Country selected other than Canada (English) $\rightarrow$ survey discontinued.

2. Are you....?
a. Male
b. Female

3. Are you...?
a. Less than 18
b. $18-34$
c. $35-54$
d. $55 \%$

4. Region:
a. Western \& Northern Canada
b. Ontario
c. Quebec
d. Atlantic Canada

5. Origin
a. North American Aboriginal origins
b. Other North American origins
c. British Isles origins
d. French origins
e. Western European origins (except French origins)
f. Northern European origins (except British Isles origins)
g. Eastern European origins
h. Southern European origins
i. Other European origins
j. Caribbean origins
k. Latin, Central and South American origins
l. Central and West African origins
m. North African origins
n. Southern and East African origins
o. Other African origins
p. West Central Asian and Middle Eastern origins
q. South Asian origins
r. East and Southeast Asian origins
s. Other Asian origins
t. Oceania origins
u. Not sure/Prefer not to say

6. What is your education level?
a. Elementary school
b. Middle school/junior high
c. High school
d. Some college/university
e. Graduated 2-year college 
f. Graduated 4-year college/university

g. Graduate school

h. Postgraduate

i. Prefer not to say

7. What is you annual household income?

a. Under $\$ 15,000$

b. $\$ 15,000-\$ 19,999$

c. $\$ 20,000-\$ 24,999$

d. $\$ 25,000-\$ 29,999$

e. $\$ 30,000-\$ 34,999$

f. $\$ 35,000-\$ 39,999$

g. $\$ 40,000-\$ 44,999$

h. $\$ 45,000-\$ 49,999$

i. $\$ 50,000-\$ 54,999$

j. $\$ 55,000-\$ 59,999$

k. $\$ 60,000-\$ 64,999$

I. $\$ 65,000-\$ 69,999$

m. $\$ 70,000-\$ 74,999$

n. $\$ 75,000-\$ 79,999$

o. $\$ 80,000-\$ 84,999$

p. $\$ 85,000-\$ 89,999$

q. $\$ 90,000-\$ 94,999$

r. $\$ 95,000-\$ 99,999$

s. $\$ 100,000-\$ 124,999$

t. $\$ 125,000-\$ 149,999$

u. $\$ 125,000-\$ 149,999$

v. $\$ 200,000+$

8. Employment
a. High managerial, administrative or professional
b. Intermediate managerial, administrative or professional
c. Supervisor; clerical; junior managerial, administrative or professional
d. Intellectual profession, Executive, Freelance
e. Intermediate profession: Public sector ( health, teaching...) companies
f. Intermediate Professional Liberal Profession
g. Farmer ( farm owner)
h. Craftman, shop owner, managing director
i. Employee, public sector companies
j. Skilled manual worker
k. Semi-skilled or unskilled manual worker
I. Housewife / Homemaker
m. Retired
n. Student

o. Unemployed

9. Are you the primary grocery shopper for your household?
a. Yes
b. No
c. Share responsibility 
10. Number of children under 18 in your household:
a. 0
b. 1
c. 2
d. 3
e. 4
f. 5
g. 6
h. 7
i. 8
j. 9
k. $10+$

11. Number of people in your household including you:
a. 1
b. 2
c. 3
d. 4
e. 5
f. 6
g. 7
h. 8
i. 9
j. $10+$

29

31

32

33

34

35

36

37

38

39

40

41

42

43

44

45

46

47

48

49

50

51

52

53

54

55

56

57

58

59

60 


\title{
Appendix B: Side Dish and Dessert Research Questions
}

\begin{abstract}
A large national fast food restaurant is interested in promoting healthy eating in children. Currently, they sell a child's meal for \$3.99. The typical child's meal contains a drink (milk or a small soft drink), an entrée (a cheeseburger, a hamburger or chicken nuggets) and a side (apple slices or french fries). If you took your child to eat a child's meal at this large national fast food restaurant, which side would you most likely choose for your child?

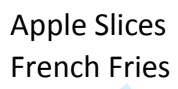

The large national fast food restaurant mentioned in the previous question, is planning it expand the child's meal to include a dessert item. If you took your child to eat a child's meal at this national fast food restaurant, which dessert item would you most likely choose for your child?

Organic Low Fat Yogurt

Small Ice Cream Cone 


\title{
Appendix C: Incentive Research Questions
}

\begin{abstract}
A large national fast food restaurant is interested in promoting healthy eating in children. Currently, they sell a child's meal for \$3.99. The typical child's meal contains a drink (milk or a small soft drink), an entrée (a cheeseburger, a hamburger or chicken nuggets) and a small side of french fries. While the restaurant currently offers apple slices as a substitute for french fries, they want to increase the number of parents that choose apple slices instead of french fries for their children.

If you took your child to eat a child's meal at a fast food restaurant, which of the following options would change the type of side dish that you normally order for your child from french fries to apple slices?
\end{abstract}

My child already eats apple slices instead of french fries, as a part of their child's meal. A $5 \%$ price discount would convince me to change my child's order to apple slices instead of french fries (The child's meal would cost $\$ 3.79$, instead of $\$ 3.99$, saving you $\$ 0.20$ )

A $10 \%$ price discount would convince me to change my child's order to apple slices instead of french fries (The child's meal would cost $\$ 3.59$, instead of $\$ 3.99$, saving you $\$ 0.40$ )

A $15 \%$ price discount would convince me to change my child's order to apple slices instead of french fries (The child's meal would cost $\$ 3.39$, instead of $\$ 3.99$, saving you $\$ 0.60$ )

A $20 \%$ price discount would convince me to change my child's order to apple slices instead of french fries (The child's meal would cost $\$ 3.19$, instead of $\$ 3.99$, saving you $\$ 0.80$ )

A $25 \%$ price discount would convince me to change my child's order to apple slices instead of french fries (The child's meal would cost $\$ 2.99$, instead of $\$ 3.99$, saving you $\$ 1.00$ )

I would always order french fries instead of apple slices for my child. No discount in the price of the meal would change my mind. 


\title{
Appendix D: Deterrents (Deterrent Research Questions and Data)
}

\begin{abstract}
A large national fast food restaurant is interested in promoting healthy eating in children.
Currently, they sell a child's meal for \$3.99. The typical child's meal contains a drink (milk or a small soft drink), an entrée (a cheeseburger, a hamburger or chicken nuggets) and a small side of french fries.
\end{abstract}

While the restaurant currently offers apple slices as a substitute for french fries, they want to increase the number of parents that choose apple slices instead of french fries for their children. To encourage parents to choose apple slices instead of french fries for their children, the restaurant is planning to add an up-charge if french fries are chosen as a part of the child's meal.

The new menu pricing will be:

\$3.99 for a child's meal with a drink, an entree and apple slices +an up-charge to substitute french fries instead of apple slices.

If you took your child to eat a child's meal at a fast food restaurant, which of the following options would change the type of side dish that you normally order for your child from French Fries to Apple Slices.

My child already eats apple slices instead of french fries, as a part of their child's meal.

A 5\% up-charge would convince me to change my child's order to apple slices instead of French Fries (The child's meal would cost $\$ 4.19$, instead of $\$ 3.99$, charging you an additional $\$ 0.20$ for substituting french fries instead of apple slices)

A 10\% up-charge would convince me to change my child's order to apple slices instead of French Fries (The child's meal would cost $\$ 4.39$, instead of $\$ 3.99$, charging you an additional $\$ 0.40$ for substituting french fries instead of apple slices)

A 15\% up-charge would convince me to change my child's order to apple slices instead of French Fries (The child's meal would cost $\$ 4.59$, instead of $\$ 3.99$, charging you an additional $\$ 0.60$ for substituting french fries instead of apple slices)

A 20\% up-charge would convince me to change my child's order to apple slices instead of French Fries (The child's meal would cost $\$ 4.79$, instead of $\$ 3.99$, charging you an additional $\$ 0.80$ for substituting french fries instead of apple slices)

A 25\% up-charge would convince me to change my child's order to apple slices instead of French Fries (The child's meal would cost $\$ 4.99$, instead of $\$ 3.99$, charging you an additional $\$ 1.00$ for substituting french fries instead of apple slices)

I would always order French fries instead of apple slices for my child, regardless of the price.

Table S1 - Cumulative percentage of respondents that would choose apple slices over french fries based on the proposed financial deterrent.

Proposed-up-charge for french fries required for respondents to change their order to apple slices

0\% Deterrent (Would order apple slices even if there was no pricing deterrent)

$5 \%$ Deterrent (\$0.20 up-charge)

$10 \%$ Deterrent (\$0.40 up-charge)

$15 \%$ Deterrent (\$0.50 up-charge)

$20 \%$ Deterrent (\$0.80 up-charge)

25\% Deterrent (\$1.00 up-charge)

Respondents would always order french fries
Percent of respondents that would select apple slices at the stated deterrent up-charge level for fries

$18 \%$
$15 \%$
$11 \%$
$14 \%$
$16 \%$
$13 \%$
$13 \%$
Cumulative \% of respondents that would order apple slices, based on the escalating deterrent up-charge level for fries

$18 \%$

$33 \%$

$44 \%$

$58 \%$

$74 \%$

$87 \%$ 


\title{
Appendix E: Deterrent Question - Price Specific
}

\begin{abstract}
A large national fast food restaurant is interested in promoting healthy eating in children. Currently, they sell a child's meal for \$3.99. The typical child's meal contains a drink (milk or a small soft drink), an entrée (a cheeseburger, a hamburger or chicken nuggets) and a small side of french fries. While the restaurant currently offers apple slices as a substitute for french fries, they want to increase the number of parents that choose apple slices instead of french fries for their children. To encourage parents to choose apple slices instead of french fries for their children, the restaurant is planning to charge an additional $\$ 0.25$ if french fries are chosen as a part of the child's meal. The new menu pricing will be: $\$ 3.99$ for a child's meal with a drink, an entree and apple slices $+\$ 0.25$ to substitute french fries instead of apple slices.
\end{abstract}

If you took your child to eat a child's meal at this fast food restaurant, would the $\$ 0.25$ up-charge for french fries change what you ordered for your child?

My child already eats apple slices instead of french fries as a part of their child's meal. The pricing change would not change our order.

A $\$ 0.25$ up-charge for french fries would change what I order for my child. I would rather order the apple slices for my child than pay the $\$ 0.25$ up-charge for french fries.

A $\$ 0.25$ up-charge for french fries would NOT change what I order for my child. I would order the french fries for my child and I would pay the $\$ 0.25$ up-charge.

I would always order french fries instead of apple slices for my child, regardless of the price. 
Page 41 of 45

British Food Journal

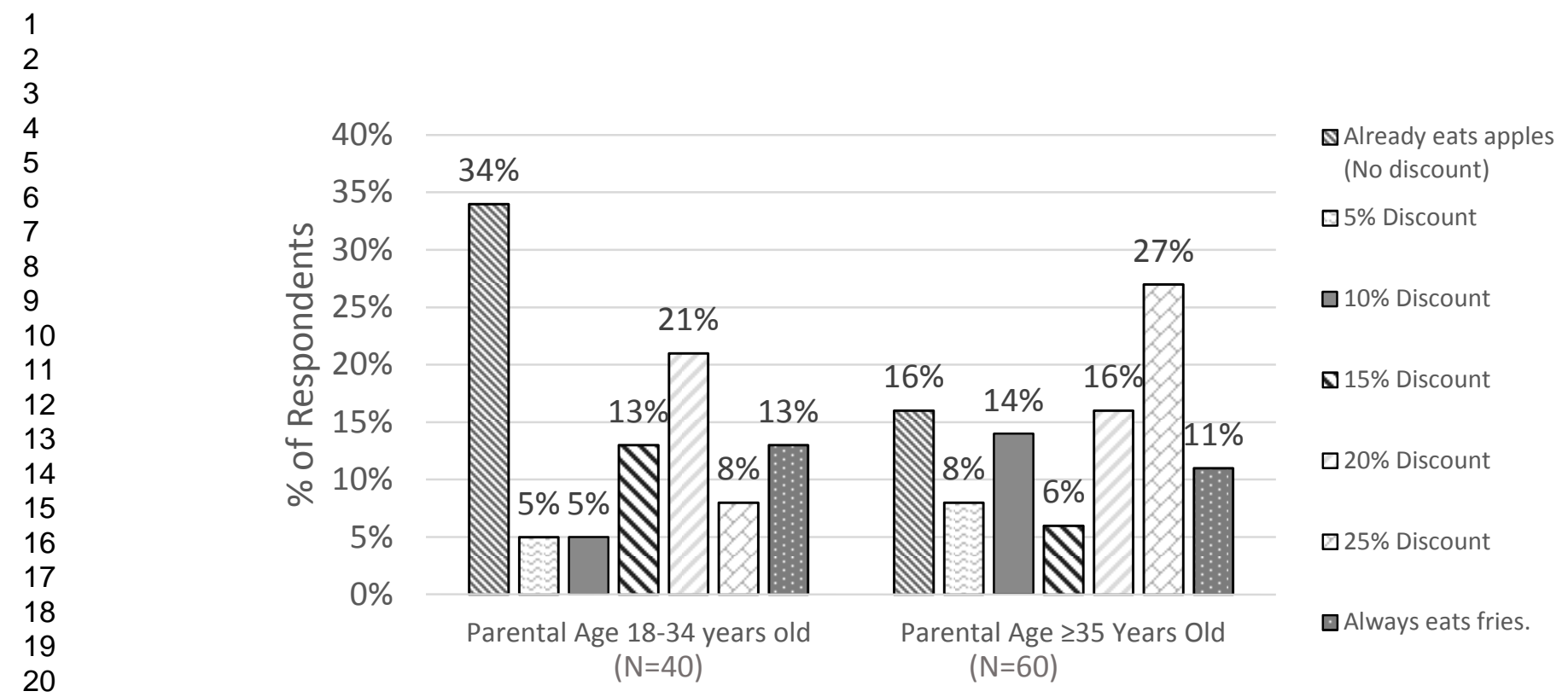

Figure 1. Incentive response to discount for healthier side option by age range, parental age 18-34 years and age $\geq 35$ years. 
Table 1. Side dish selected by parental age.

$\begin{array}{lcc}\text { Respondent Group } & \text { Apple Slices } & \text { French Fries } \\ \text { Parents 18-34 years old } & 51 \% & 49 \% \\ \text { Parents } \geq 35 \text { years old } & 27 \% & 73 \% \\ \text { Total Respondents } & 38 \% & 62 \%\end{array}$

10

11

12

13

14

15

16

17

18

19

20

21

22

23

24

25

26

27

28

29

30

31

32

33

34

35

36

37

38

39

40

41

42

43

44

45

46

47

48

49

50

51

52

53

54

55

56

57

58

59

60 
1

2

3

4

5

6

7

8

9

10

11

12

13

14

15

16

17

18

19

20

21

22

23

24

25

26

27

28

29

30

31

32

33

34

35

36

37

38

39

40

41

42

43

44

45

46

47

48

49

50

51

52

53

54

55

56

57

58

59

60

Table 2. Chosen dessert item selected with apple or french fry side order.

\% of Respondents Chosen Side and Dessert Combinations

42\% French fries and ice cream cone

22\% Apple slices and organic low-fat yogurt

20\% French fries and organic low-fat yogurt

$16 \%$ Apple slices and ice cream cone 
Table 3. Cumulative percentage of respondents that would choose apple slices over french fries based on the proposed financial discount.

Proposed discount required for respondent to change The \% of respondents their order from french fries into apple slices

0\% Discount (Would order apple slices even if no discount was offered)

5\% Discount

$10 \%$ Discount

$15 \%$ Discount

$20 \%$ Discount

25\% Discount

Respondents would always order french fries that would select apple slices at the

stated discount level

$23 \%$

$7 \%$

$11 \%$

$9 \%$

$18 \%$

$20 \%$

$12 \%$
Cumulative \% of respondents that would select apple slices, based on the escalating discount level

$30 \%$

$41 \%$

$50 \%$

$68 \%$

$88 \%$ 
Page 45 of 45

British Food Journal

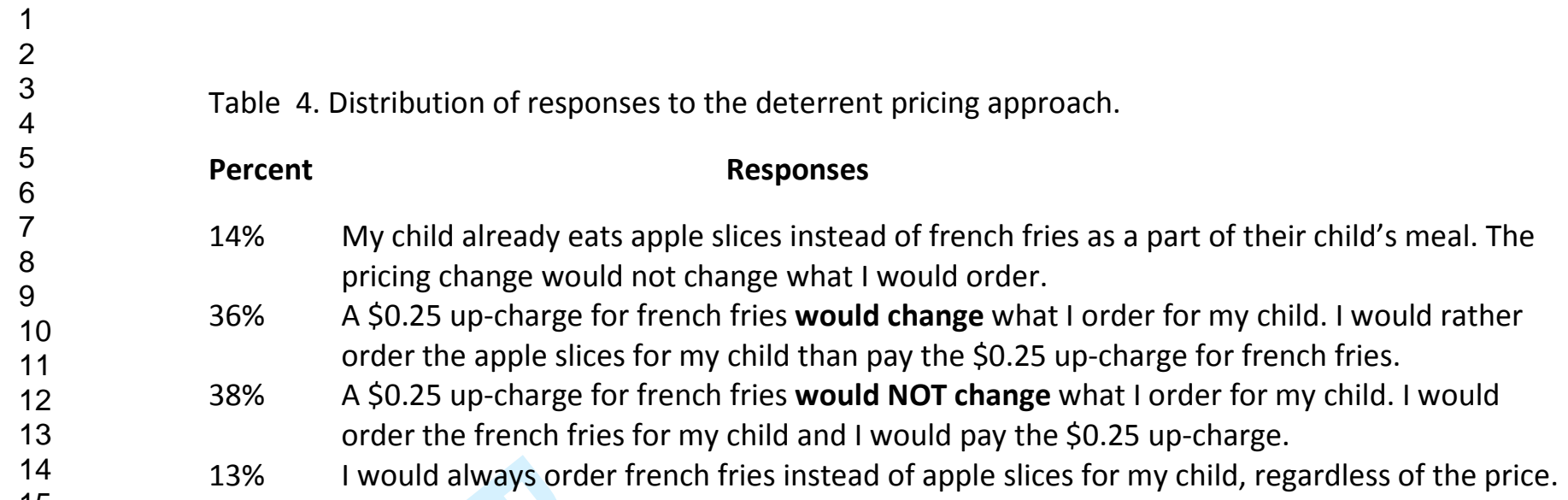

